EN DEBATE Rev Chil Salud Pública 2014; Vol 18 (2): 206-209

\section{MANUEL ALMEYDA Y EL DERECHO A MORIR}

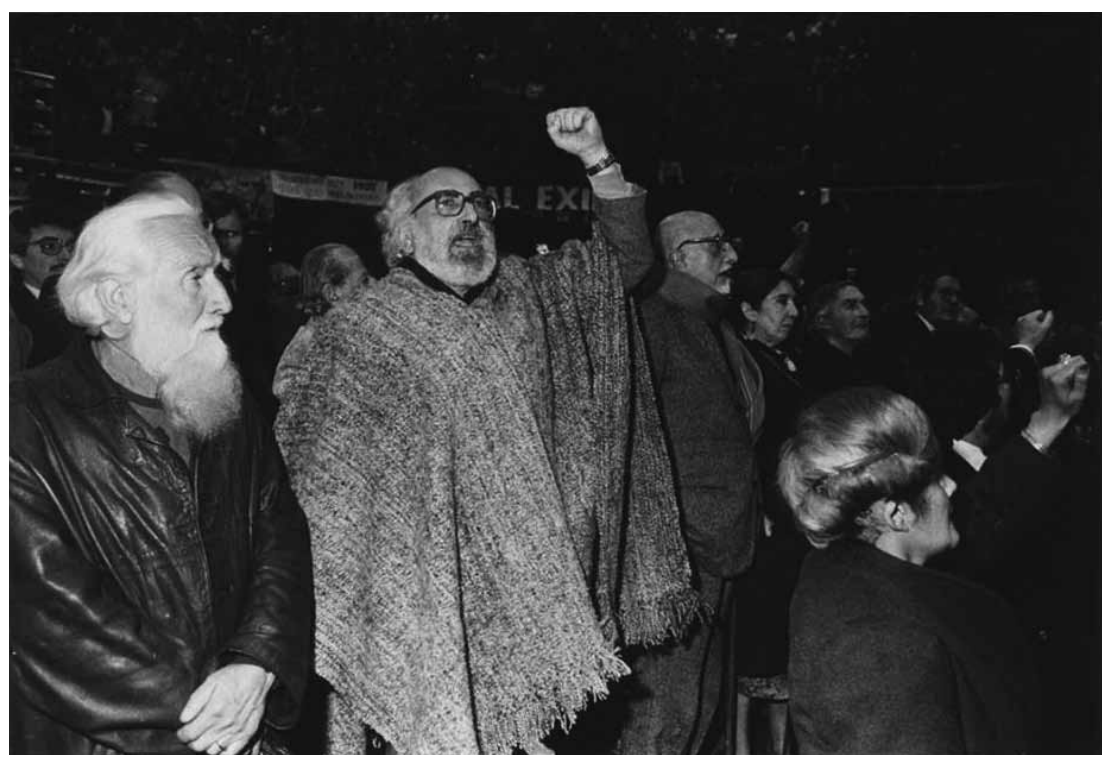

\title{
PRESENTACIÓN
}

Esta sección busca introducir y documentar problemas de Salud Pública que nacen en forma pública, con la presencia de legos y expertos, por su relevancia y conformación.

En enero de este año, el Dr. Manuel Almeyda, a los 89 años, dirigió al Colegio Médico la carta que publicamos, pidiendo un debate acerca de las condiciones de una muerte voluntaria, como médico y como enfermo, viviendo una vida que calificó como insufrible e indigna. Su muerte ocurrió el 15 de enero.

Hay en su carta y en su gesto de negarse a ingerir alimentos en los días finales de su existencia, las señas de una actitud en que convergen la medicina y la política, dos de las pasiones de su vida. Su carta nos llama a un hablar, pero primordialmente a un escuchar esta voz. Y a partir de ella, re-escuchar las múltiples voces de ancianos y niños, enfermos en condiciones irrecuperables, (muchas veces no "terminales"), de solitarios y abandonados.

El Dr. Manuel Ramón Almeyda Medina nació el 25 de agosto de 1924 en Santiago. La combinación de medicina (tanto clínica como de salud 
pública) y militancia socialista que constituyó su vida, nos parecen presentes en su carta y en su abordaje de la dura condición de enfermo.

El Dr. Almeyda ingresó a la Brigada Universitaria Socialista en 1945, y luego fue dirigente nacional del Partido Socialista. Estudió en el Liceo Alemán de Santiago. Posteriormente ingresó a la Universidad Católica de Santiago, y luego a la Universidad de Chile, donde se tituló de médico cirujano en 1951 con la tesis Acción del tiosorbitol sobre la vasopresina, dirigida por Héctor Croxatto, la que fue evaluada el 16 de agosto con 20 puntos de un máximo de 21.

En 1954 obtuvo el título de especialista en Salud Pública con la tesis Organización de la primera sesión de auditoría médica en el Hospital de San Antonio. Entre 1952 y 1954 fue médico de la Dirección General de Sanidad en San Antonio. Más tarde fue nombrado director del Hospital de Rancagua y del Área de Salud de la misma ciudad.

En diciembre del año 1973 fue exonerado de sus funciones en el Hospital José Joaquín Aguirre.

Comenzó a trabajar en el Comité ProPaz, aproximadamente en 1976, para continuar luego en la Vicaría de la Solidaridad, tarea que dejó para dedicarse a la dirigencia política del MDP (referente político nacional que agrupó al PC, al MIR, al PS-Almeyda, al PS 24 Congreso y a sectores del MOC y del MAPU), en 1983.
En 1981 es detenido y permanece recluido e incomunicado por casi un mes en un recinto secreto de la CNI desde donde es trasladado a la cárcel de Valparaíso.

En 1984 el Partido Socialista habría tomado la decisión de que Manuel Almeyda entrara a la clandestinidad. Luego en 1987, el PS determina su exilio en Berlín oriental.

Regresa del exilio en 1990-1991 y trabaja como Secretario General del PS hasta 1993.

En 1992, se presenta como candidato para la alcaldía de La Florida. A partir de esa fecha, sigue participando en las actividades del partido, pero sobre todo en el funcionamiento de la Casa Canadá, que posteriormente se transforma en la Fundación Clodomiro Almeyda.

Con el tiempo, fue delegando responsabilidades para dedicarse a sus grandes pasiones, leer, aprender y estudiar. De la gran cantidad de temas científicos que lo inquietaban, la física y la creación del universo pasaron a ocupar un lugar preponderante en su vida, y es así como decide escribir un ensayo sobre la existencia del hombre y su evolución hacia un hombre nuevo. Este ensayo fue pensado para la familia y los amigos, pero dada su condición de documento de interés, este año será publicado por la Universidad de Chile.

Los invitamos a leer su carta y a través de ella, y de su existencia, ayudarnos a pensar y a resolver los desafíos del presente.

Rocío Almeyda y Yuri Carvajal 
Santiago,Enero, 2014

\section{Dr. Enrique Paris}

Presidente del Colegio Médico de Chile

Presente

Estimado Dr. Paris:

Necesito plantearle un problema, en la esperanza que con su participación se logre encontrar una solución.

Tengo 89 años $y$ desde hace algunos años sufro una insuficiencia respiratoria y cardiaca junto a otros problemas propios de mi edad. Desde hace algunos meses mi situación se ha agravado haciéndome oxigeno dependiente y con incapacidad para movilizarme. Cada dia que pasa mi deterioro es mayor impidiéndome realizar hasta las actividades habituales e incluso leer.ta vida que tengo es insufrible e indigna como es la que llegan a tener las personas en mis mismas condiciones.

Esa es la razón por la que le quiero proponer a usted que el Colegio Médico promueva la creación de una comisión de hombres justos que estudien la mejor forma de poner término a la vida de las personas que estén en una condición de vida terminal y que asi lo deseen.

Esta forma justa y digna de poner fin a la vida de quien sufre ya un daño irreparable, se ajusta a los derechos humanos que cualquier ciudadano deberia tener. Lo demuestran asi los paises que tras largas discusiones han incorporado en su legislación esta posibilidad como son Bélgica, Suiza, Inglaterra, algunos estados de Estados Unidos y Australia. Incluso en América Latina hay paises que de alguna u otra forma se han preocupado del problema y le han dado alguna salida.

Esperando usted acoja esta solicitud para que nuestro pais tambièn legisle al respecto, le saluda atentamente,

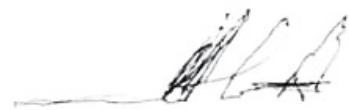

DR. Manuel Almeyda Medina

RUT 1886271.9 


\section{UNA CARTA MODESTA Y AMBICIOSA A LA VEZ}

La Ley 20.584 se entrampó desde los primeros debates realizados hace más de doce años por iniciativa de la ministra de Salud Dra. Michele Bachelet, en el problema de la autonomía del paciente y si acaso era éticamente legítimo desconocerla cuando su decisión de omitir tratamiento implicaba la aceleración de la muerte. Para unos, era la puerta de entrada de la eutanasia médica, para otros, siempre en minoría, nos parecía arbitrario e impresentable limitar las decisiones voluntarias y competentemente expresadas, de no continuar con medidas terapéuticas que atrasaban la muerte y prolongaban el proceso de vida residual cargada de sufrimientos. En los doce años que demoró la legislación y promulgación de la ley, fue este el tema que mantenía polémicas insalvables, terminando con presentar a la ciudadanía una ley defectuosa en lo jurídico y en lo ético, de un conservadurismo paternalista que excluye el asentimiento informado de los legalmente menores de edad, y cercena la autonomía del paciente cuando solicita que la medicina le ayude a morir en vez de empecinarse en mantener una vida indeseada de sufrimiento y desesperanza.

Todos los argumentos palidecen frente al testimonio del Dr. Manuel Almeyda, quien solicita al Colegio Médico establecer un comité de "hombres buenos" para abrir el debate sobre eutanasia médica en pacientes en estado avanzado de enfermedad irreversible, intratable, cargada de sufrimientos vividos como insoportables: lo que con tan poca gracia y gusto los médicos denominamos "enfermos terminales".

La carta del Dr. Almeyda es modesta y ambiciosa a la vez. Modesta por cuanto solicita nada más que la apertura al debate, ambiciosa porque propone un comité de personas capaces de debatir sin prejuicios, sin doctrinas estrechas, con apertura a los problemas de una ciudadanía que quiere ver respetadas sus opiniones y decisiones en el ámbito privado que solo a cada individuo compete.

Hace ya algunos años publiqué en la $R e-$ vista Chilena de Salud Pública, la convicción de que el tema eutanasia requiere un debate ciudadano que lleve a una política pública legitimada. Es, por lo tanto, materia en que la salud pública no debe seguir mirando para el lado. Sea el documento póstumo del Dr. Almeyda una voz más, en apoyo de los que solicitamos, no que se apoye o siga prohibiendo la eutanasia, sino que se abra la deliberación con argumentos racionales y razonables.

Miguel Kottow Unidad de Bioética y Pensamiento Biomédico Escuela de Salud Pública 